\title{
Review of: "Efficient open recruitment and perspectives of host families on medical student homestays in rural Japan"
}

Tipaporn Thongmak

Potential competing interests: The author(s) declared that no potential competing interests exist.

This is an interesting research of community-based medical education program. There are some points that the study could more clarify

1. The homestay is the part of program, which every medical students to learn or an elective part in community based program.

2. What is the primary objective for this program to send the medical student to live in homestay and what are the activities of the host and students in this program ?

3. How the homestay help the students to stay in close contact with local resident for a long time

4. In the result part: how the conversation topics related with the homestay experience, the author should give more detail in the discussion part.

5. In the discussion part: how the questionnaires link to the perspectives of the host, could the authors have more detail about the experience of recruitment method.

6. More detail in the VAS scores for support the good experience of host.

7. The duration of the homestay is shorter than other studies of community based medicine, what is the evidence support of the short program 